\title{
Analysis on the Innovative Thinking Ability Enhancement with the Application of E-learning in SLA
}

\author{
Chenxin Zhou ${ }^{1, a, *}$, Chuanfei Liang ${ }^{1, b}$ \\ ${ }^{1}$ Tourism and Management Department, Wuhan College of Foreign Languages and Foreign Affairs, \\ Luoyan Street, Wuhan, China \\ ${ }^{2}$ Tourism and Management Department, Wuhan College of Foreign Languages and Foreign Affairs, \\ Luoyan Street, Wuhan, China \\ a zhouchenxin110@126.com, ${ }^{\mathrm{b}}$ 289532278@qq.com \\ * Corresponding author: Chenxin Zhou
}

Keywords: Innovative thinking ability, E-learning

\begin{abstract}
In the recent years, new pedagogical theories as well as computer-based educational technology have been adopted in China as an important supplementary aid to the second language acquisition(SLA) teaching. E-learning referring to electronic learning breaks out of the classroom setting and makes learning virtually anywhere possible. This paper is going to analyze whether e-learning has positive effect on second language learners' study. The results from the students' after-class feedback have shown that the implementation of e-learning programs are warmly welcomed because it increases productivity and allows learners to accomplish their tasks in more effective ways. Also learners' self-study ability, collaboration spirit and learning motivation are improved with the help of e-learning. It is hoped that the implementation of this new teaching mode can further promote the integration of modern educational technology and the second language teaching.
\end{abstract}

\section{Introduction}

Accompanying with the updating modern educational technology, the traditional classroom teaching has experienced significant reformation. E-learning concept was first put forward by Bernard Luskin to mean "electronic, engagement, exploration, extension, experience, extend, effective and ease of use". Nowadays educational technology based on e-learning concept is widely applied in the class practice of facilitating learning and improving performance by creating, using and managing appropriate technological processes and resources [1].

Digitized networking educational program started in the mid-1980s. At the beginning, educational institutions took advantage of the new medium to offer distance learning courses for the non-full-time students. Later on, e-learning programs based on computer-supported collaborative learning (CSCL) has developed, which encouraged online knowledge sharing. The Open Courses began a revolution of using the Internet to deliver learning [2], making heavy use of web-based training, online distance learning and online discussion among students [3]. In 2007 Salman Khan set up a well-known non-profit organization called "Khan Academy" with the mission of providing free world-class education to anyone, anywhere. Using online resources such as Khan Academy or TED Talks can help students spend more time on specific aspects of learning at home [4]. In the 
21 st century, the extensive use of computer- and web-based courses in worldwide education, such as the Flipped Classroom, Blending Learning, and Just in Time Teaching, provides learners with individualized courses for better differentiating learning practice and allows learners to work for mastery at their own pace. Although some aspects of a classroom setting are missed by using those online resources, they are helpful tools to complete the educational system [2].

In the meanwhile, the online learning and management platforms are constructed to build up good e-learning environment for the learners. Nowadays Media Core Video Learning Platform, EFront Learning, Edmodo, Flipped Lessons, Blackboard, Moodle, Sakai are the well-known elearning platforms [1]. With handheld computers, MP3 players, notebooks, mobile phones and tablets in hands, students can easily access the learning materials only if they can connect the communication signal, which brings strong portability by replacing printed books with small devices.

On the education platforms, students could have fast browsing experience by watching tailored micro-learning videos ahead of class and get real homework done through collaborating learning because sharing information and getting instant feedback is almost instantaneous among everyone using the same learning contents. And the classroom time is now used for fast assessment about homework, assimilation-oriented discussion, demonstration and peer evaluation, all of which intend to cultivate students' innovative thinking ability, self-study ability and problem-solving ability.

Due to the evaluation system reform in higher education, students' performance in tests is not the only criterion in judging one's ability and competence, their innovative thinking ability, collaborative learning ability and other skills also play an important part. Among all, innovative thinking ability is the core. Students' innovative thinking is the ability to have new and original spirit to find something new in multiple fields. It doesn't mean they have to think like scientists or inventors but to be independent and know his own mind. Thus, the e-learning approach focusing on "study to thinking, study to innovating" could be blended with the traditional L2 classroom teaching to promote better teaching effect [5].

As to the educational assessment in the e-learning class, teachers could use both the summative assessment and formative assessment to track student learning progress. Summative assessments are more common to use because they take the form of tests with specific grading schemas so teachers can give students immediate feedback on their exam performance, which is direct and convenient for teachers to know how well their students have learnt [3]. Formative assessment is more difficult as teachers have to observe and note down students' learning difficulties during the learning process. The classroom response system(CRS) used in e-learning class has helped some teachers make their formative assessments better like Quizzler, Turning Systems, etc. Depending on the software technology, the answers will be shown on a graph so students and the teacher can see the percentage of students who gave each answer and the teacher can focus on what went wrong [2]. This allows students' learning process to be subjected to observation, evaluation and supervision, thus contributing to the enhancement of their learning efficiency. The following part will illustrate what e-learning programs would be used in the L2 classroom, how to embed the e-learning programs into the L2 classroom teaching and how to make a balance between knowledge acquiring and creative thinking ability training.

\section{Implementation of E-learning in SLA}

According to the College English Curriculum Requirements (2007), the teaching objective of College English is to develop students' ability to use English in a well-rounded way, especially in listening and speaking aspects so that they will be able to communicate naturally with foreigners when needed, and at the same time enhance their ability to study independently and improve their 
cross-culture awareness.

Using computers or other forms of technology can make students practice on core skills and the teacher can work with students and conduct assessment in the meantime [1][2]. The extent to which e-learning assists or replaces other learning and teaching approaches is variable [1][2]. In L2 class "hybrid learning" approach is applied, which means e-learning program is mainly used before and after class as an supplement to the traditional classroom time. In the experiment, 32 non-English major first year college students whose English scores of College Entrance Examination are about 80 on average have been chosen and divided into two groups: the experimental group of 16 students and the contrast group of 16 students. The teacher applies two kinds of teaching approaches: the hybrid learning approach for the experimental group and the traditional classroom teaching for the contrast group. The pre- and post- tests and interviews are used to reveal whether the use of language apps on mobile devices has positive effect on learning or not [6].

\subsection{Language E-Learning Tools}

In order to guarantee learning effect, the e-learning tools that the teacher chosen much be convenient to use, easy to arouse learners' interest and appropriate to their learning proficiency level. Therefore the following well-selected L2 learning tools will be applied to those experimental group students, all of which intend to cultivate students' self-study ability, collaborative ability and innovative thinking ability. In the L2 hybrid e-learning approach, in-class time will be focused on the classroom interaction and activities between the teacher and the students while extra-class time is used by students themselves to finish assigned e-learning tasks under teacher's supervision.

\subsubsection{Listening Apps}

Radio and audio programs over the internet with webcasts and podcasts can be of great help to students' listening skills. Video technology has included VHS tapes and DVDs, as well as ondemand and synchronous methods with digital video via server or web-based options like streamed video from YouTube, Teacher Tube and Skype. Interactive digital video games can be used at higher education institutions [2].

Discovery learning is an inquiry-based learning method. Learning comes from thinking while thinking comes from question. In the e-learning classroom, the desire for knowledge is the result of the questions and doubts from the real life. So it's important for the students to follow the hot spots of society. For the experimental group students, the teacher recommends them to listen to slow speed VOA or BBC broadcasting programs. Every student has his or her own learning requirements, and a radio streaming programs provide enough resources and flexibility to accommodate this diversity [7]. Every week students have to choose at least one piece of news from the listening materials and do dictation task. In class several students are randomly picked out to read the news they've taken down notes in front of all the classmates. By listening to those VOA and BBC news, students could form a good habit of catching up with the latest news and paying close attention to what happens in the world. They will know that English is just like their mother tongue which could be used as a tool to open their mind and see the world in a new angle. Besides, TED Talks and Open Class resources are uploaded by the teacher on the Lan Mo Cloud Class Platform from time to time for students to watch after class. Given various choices of extra-class learning materials, students will gradually learn to take responsibility of their own study instead of being the passive receivers of knowledge.

\subsubsection{Speaking and Writing Apps}

The famous psychologist E.P. Torrance once said that if we are to develop ability and foster creativity, we need to provide a friendly and encouraging environment so as to make students' creative competence prosperous [8]. A relaxed, harmonious and creative environment will help 
students to think better and learn better. In fact, English Fun Dubbing software is an interesting and functional language learning application, with which students can imitate the original sounds from the English movies, songs, poems, and speeches and dub for their favourite ones alone or with partners. The difficulty level of the dubbing tasks goes from the easiest to the hardest in a continuity. Students should start with the dubbing tasks that are suitable to their English proficiency level. It's a good way to imitate pure British and American accent, deepen their knowledge of western culture and learn to collaborate with others.

For the 16 students from the experimental group, students are allowed to choose one piece of dubbing tasks every week from the English Fun Dubbing resource platform on their own. In class the teacher will demonstrate two or three students' dubbing works and ask for other students' comments. After class, students can also listen to their classmates' dubbing works with mobile phone and give comments and tips to each other. Under the competitive learning environment, students work harder to make an excellent dubbing job so as to win praise and admiration from their peers. According to some studies, the students are better at critiquing and editing written work that is exchanged over a computer network with students they know. Thus, social networking encourages collaboration and engagement and can be a motivational tool for self-efficacy amongst students [9].

\subsubsection{Reading and Translating Apps}

Shanbay application is a popular e-learning platform for students to memorize English vocabulary as well as do reading and translating tasks. At the beginning of the class, every student have to download Shanbay application on their mobiles and make learning goals, for example how many English words to memorize and how many pieces of news to read and translate each day. Then, the teacher will set up a learning group in Shanbay and invite the 16 students to join in the learning group. Everyday students have to spend some time browsing the news and memorizing the words in accordance with their learning goals. If they have achieved the goal, they can mark on the digital calendar in the application. Every 50 days of continuous marking on the calendar will be rewarded with a virtual medal from the Shanbay application organizers, which is a good stimulus for students and can help them build confidence and perseverance in L2 learning. Meanwhile the teacher could easily keep the track of every student's learning process or learning efficiency and remind those students who forget to study and mark the calendar. Group learning allow learners and educators to post thoughts, ideas, and comments on Shanbay in an interactive learning environment [10][11][12]. Besides, social networking sites are virtual communities for students interested in a particular subject to communicate by voice, chat, or instant message [10].

\subsection{Language E-Management Tools}

In the e-learning class, the teacher will supervise students' learning behaviour through a free and open e-learning platform-Lan Mo Cloud Class Application. Before class the teacher will design a 10-minute micro-course video about the selected content from the textbook and upload it to the Lan Mo Cloud Class Application. Also the teacher will upload the audio recordings of the new words, expressions and dialogues into the Lan Mo Cloud Class Application. Students have to watch the videos first, read the vocabulary and sentences and record their own audio files before class. Though the Lan Mo Cloud Application platform, the teacher can observe how many students have finished the tasks and what problems are common for those students according to the date collected automatically. In class the teacher could discuss with students and solve the difficult problems. After class, students are required to sum up what they've learnt from the class on the learning platform. As a learning management tool, the Lan Mo Cloud Class software will keep recording students' online self-learning data and keep files on students' study results, which is an efficient and accurate formative assessment method. 


\section{Conclusions}

After the introduction of concept, development and different e-learning approaches, this paper makes an experimental study of implementing an e-learning mode in the College English course. Based on the data collected from students' audio files and feedbacks, about 80 percent of the interviewed students prefer the e-learning approach to the traditional class. They report that some educational apps can improve group work by allowing them to receive feedback on answers and promoting collaboration in solving problems, such as English Fun Dubbing and Shanbay application [13]. They also agree that after using the computer-based learning apps they can learn more in less time and are more willing to participate in those activities. They can independently solve problems and accomplish their tasks in more effective ways. The statistics from the final exam showed that the average scores of the experimental group students are $21 \%$ higher than those of the contrast group students, especially in the listening part $(25 \%$ higher) and reading part (23\% higher) which is a prove that e-learning education increases learning productivity and has positive effect on L2 learning.

Nowadays, fierce competition from the society calls for creative thinking and innovate talent especially for IT industry. Nathan Marsh Puse, Harvard University president, believes that "whether a person with innovative thinking is the watershed between first-class professionals and third-rate talent.'[14] In order to improve the quality of education, the educators should cultivate students' innovative ability as well as creative thinking. In the process of e-learning programming teaching, teachers should make sure that the computer software programs are up-to-date and tailored to students' level so as to improve students' learning interest. At the same time, students should make the most of those valuable information from the e-learning programs. The well-organized online learning programs will create an area in which students' interests, hobbies and talents will be met so that they can be the final winners in the fierce competition in the information age.

Since the limitation of time, there are some shortages in the research. For instance, the number of students participating in the e-learning is limited. Further studies are needed on how to better embed the e-learning programs with the traditional L2 instruction. We hope this paper throws some new light upon the innovation of L2 teaching in the process of College English teaching reform.

\section{References}

[1] Robinson, Rhonda, Molenda, Michael, Rezabek, Landra. "Facilitating Learning" (PDF). Association for Educational Communications and Technology. Retrieved 18 March 2016.

[2] Dekel, Gil. "So, what does a Learning Technologist do?". Retrieved 3 July 2006.

[3] Richey, R.C. (2008). "Reflections on the 2008 AECT Definitions of the Field". TechTrends. 52 (1): 24-25. doi:10.1007/s11528-008-0108-2.

[4] Day, R., Payne, L. “Computer-managed instruction: an alternative teaching strategy.” J Nurs Educ. 26: 30-36. PMID 3029349.

[5] Clifton F. Conrad, Jason Johnson and Divya Malik Gupta. (2007). Teaching-for-Learning (TFL): A Model for Faculty to Advance Student Learning. Innovative Higher Education. Volume 32, Number 3, 153-165.

[6] “Second Life Nursing Simulation”. YouTube. 2009-09-16. Retrieved 2013-10-22.

[7] Float. "mLearning Is Not eLearning on A Mobile Device - Float".

[8] David F. Treagust. (2007). Research-based Innovative Units for Enhancing Student Cognitive Outcomes and Interest in Science. Roser Pintó, Digna Couso (Eds), Contributions from Science Education Research. Springer Netherlands, 11-26.

[9] Fiedler, Sebastian., Väljataga, Terje (2011). "Personal learning environments: concept or technology?”. 
[10] Al Januszewski A., Molenda Michael. (2007) Educational Technology: A Definition with Commentary. ISBN 978-0805858617.

[11] “Technology in Education: An Overview - Education Week". www.edweek.org. Retrieved 2016-10-31.

[12] Selwyn, N. (2011) Education and Technology: Key Issues and Debates. London: Continuum International Publishing Group.

[13] Moore, J.L., Dickson-Deane, C., Galyen, K. (2011). "E-Learning, online learning, and distance learning environments: Are they the same?". The Internet and Higher Education. 14 (2): 129-135. doi:10.1016/j.iheduc. 2010.10. 01 .

[14] Nandasara S.T., Samaranayake V. K. and Yoshiki Mikami. (2006). Revolutionary Development of Computer Education- A Success Story. IFIP International Federation for Information Processing- History of Computing and Education 2 (HCE2). Volume 215, 167-180. 